\section{Biological activities of Juglans regia flowers}

\section{Seyed Fazel Nabavi, ${ }^{1}$ Mohammad Ali Ebrahimzadeh, ${ }^{* 2}$ Seyed Mohammad Nabavi, ${ }^{3}$ Mitra Mahmoudi, ${ }^{2}$ Shabnam Keyvani $\boldsymbol{R a d}^{2}$}

${ }^{1}$ National Elites Foundation of Iran, Tehran, Iran,

${ }^{2}$ Pharmaceutical Sciences Research Center and Traditional and Complementary Medicine Research Center, School of Pharmacy, Mazandaran University of Medical Sciences, Iran,

${ }^{3}$ Department of Biology, University of Mazandaran, Babolsar, Iran.
Revista Brasileira de Farmacognosia Brazilian Journal of Pharmacognosy 21(3): 465-470, May./Jun. 2011

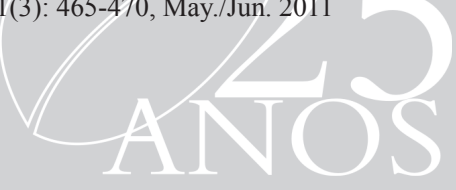

\section{Article}

Received 9 Jul 2010

Accepted 6 Nov 2010 Available online 3 Jun 2011

Keywords: antidepressant activity, antihypoxic activity antioxidant activity Juglans regia $\mathrm{mL}^{-1}$ ). It exhibited low antioxidant activity in linoleic acid peroxidation test. Its pharmacological effects may be attributed, in part, to the presence of phenols and flavonoids in the extract.
ISSN 0102-695X doi: $10.1590 / \mathrm{S} 0102-695 \mathrm{X} 2011005000092$

\section{Introduction}

Juglans regia L. (Persian walnut) is a deciduous tree from Juglandaceae family. Its fruits are consumed as food, which are rich unsaturated fatty acids. Walnut leaf has been widely used in traditional medicine for the treatment of skin inflammations and ulcers and for its antidiarrheic, antihelmintic, antiseptic and astringent properties (Almeida et al., 2008). Anti-inflammatory, antinociceptive and antidiabetic activities of walnut leaves (Erdemoglu et al., 2003; Asgary et al., 2008), antioxidant effects of its seeds and radical scavenging of leaves have been previously reported (Almeida et al., 2008, Fukuda et al., 2003). However, there is no scientific report on biological activity of $J$. regia flower. In the present study, the antioxidant, antidepressant, anti-inflammatory and anihypoxic activities of methanol extract of $J$. regia flowers were evaluated. Its gallic acid, coumarin and quercetin contents were determined by HPLC/DAD. A possible relationship between the chemical composition and the biological and pharmacological potential was considered.

\section{Materials and Methods}

Plant material and preparation of freeze-dried extract
Juglans regia L., Juglandaceae, flower was collected from Dashtenaz area, Sari, Iran, in 2008 and identified by Dr. B. Eslami. A voucher specimen was deposited with the Sari school of pharmacy herbarium (No 629). Sample was dried at room temperature (r.t.) and ground before extraction. $100 \mathrm{~g}$ of sample was extracted by percolation with methanol $(400 \mathrm{~mL} \times 3)$ for $24 \mathrm{~h}$. The resultant extracts were concentrated in a rotary evaporator until a crude solid extract was obtained (24\%).

\section{Animals}

Male Swiss albino mice (20-24 g) or male Wistar rats (180-220 g), obtained from Institute Pasteur of Iran were used in this study. The animals were housed in standard cages with free access to food and water. Experimental protocols met the guidelines of animal experimentation approved by the commission of ethics in animal experimentation of Mazandaran University of Medical Sciences. All experiments were conducted between 10 am and $2 \mathrm{pm}$.

\section{Anti-inflammatory effect}

Carrageenan-induced hind paw edema model and toxicity test were carried out according 
to our published papers (Ebrahimzadeh et al., 2006; Ebrahimzadeh et al., 2007; Mahmoudi et al., 2010). Extract or diclofenac sodium was administered i.p. to rats $1 \mathrm{~h}$ before carrageenan injection. The volume of edema was measured prior and $3 \mathrm{~h}$ after carrageenan injection.

\section{Anti hypoxic activity}

Haemic hypoxia

Twenty four mice were divided into four groups. Control group was treated with $0.9 \%$ saline solution. Thirty minutes after i.p. administration of extract $31.25,62.5$ and $125 \mathrm{mg} \mathrm{kg}^{-1}, \mathrm{NaNO}_{2}\left(360 \mathrm{mg} \mathrm{kg}^{-1}\right.$ ) was applied i.p. to each mouse and antihypoxic activity was estimated as the latent time of evidence of hypoxia in minutes (Ebrahimzadeh et al., 2010a; Ebrahimzadeh et al., 2010c).

\section{Circulatory hypoxia}

Twenty four mice were divided into four groups. Groups were treated with $0.9 \%$ saline solution. Thirty minutes after i.p. administration of extract 62.5, 125 and $250 \mathrm{mg} \mathrm{kg}^{-1}, \mathrm{NaF}$ (150 $\mathrm{mg} \mathrm{kg}^{-1}$ ) was applied i.p. to each mouse and the antihypoxic activity was estimated in minutes as the latent time of evidence of hypoxia (Ebrahimzadeh et al., 2010a; Ebrahimzadeh et al., 2010c).

\section{Antidepressant activity}

\section{Forced swimming test (FST)}

Mouse was dropped into glass cylinder and left there for $6 \mathrm{~min}$. The duration of immobility during the final 4-min interval of the swimming test was measured (Mahmoudi et al., 2009). Control groups were treated with saline solution. Other groups received an i.p. injection of extract $(250-1500 \mathrm{mg} / \mathrm{kg})$ in saline solution and imipramine $(15 \mathrm{mg} / \mathrm{kg}) 1 \mathrm{~h}$ before the experiment.

\section{Tail suspension test (TST)}

Groups of ten animals received an i.p. injection of extracts $(250-1000 \mathrm{mg} / \mathrm{kg})$ in saline solution and imipramine $(15 \mathrm{mg} / \mathrm{kg}), 30 \mathrm{~min}$ before the experiment. Mice are suspended on the edge of a shelf $58 \mathrm{~cm}$ above a table top by adhesive tape placed approximately $1 \mathrm{~cm}$ from the tip of the tail. The duration of immobility is recorded for periods of 5 min (Mahmoudi et al., 2009).

Maximum non-fatal dose
Different doses of extract were injected to separated groups of seven. After $48 \mathrm{~h}$, the highest dose that did not induce any mortality was considered as the maximum non-fatal dose (Ebrahimzadeh et al., 2010c).

Determination of total phenolic compounds and flavonoid content

Total phenolic compound contents were determined by the Folin-Ciocalteau method (Ghasemi et al., 2009). Results were expressed as gallic acid equivalent from a calibration curve. Total flavonoids were estimated as previously described (Ghasemi et al., 2009). Total flavonoid contents were calculated as quercetin equivalent from a calibration curve.

\section{Antioxidant activity}

\section{DPPH radical scavenging activity}

The stable 1,1-diphenyl-2-picryl hydrazyl radical (DPPH) was used for determination of free radical scavenging activity of the extracts (Dehpour et al., 2009). Vitamin C, BHA and quercetin were used as standard controls.

\section{Determination of metal chelating activity}

The ability of extract to chelate ferrous ions was estimated by our recently published papers (Ebrahimzadeh et al., 2008; Ebrahimzadeh et al., 2009). The percentage inhibition of ferrozine- $\mathrm{Fe}^{2+}$ complex formation was calculated as $\left[\left(\mathrm{A}_{0}-\mathrm{A}_{1}\right) / \mathrm{A}_{0}\right] \times 100$, where $\mathrm{A}_{0}$ was the absorbance of the control and $A_{1}$ was the absorbance of the mixture, containing the extract or the absorbance of EDTA.

\section{Assay of nitric oxide-scavenging activity}

Sodium nitroprusside $(10 \mathrm{mM})$ was mixed with different concentrations of extract dissolved in water and incubated at r.t. for $150 \mathrm{~min}$. After the incubation period, $0.5 \mathrm{~mL}$ of Griess reagent was added. The absorbance of the chromophore formed was read at $546 \mathrm{~nm}$. Quercetin was used as positive control (Ebrahimzadeh et al., 2010b; Ebrahimzadeh et al., 2010d).

\section{FTC Method}

Determination of antioxidant activity by the

The method was adopted from our recent paper (Nabavi et al., 2008). The absorbance of final red solution was measured at $500 \mathrm{~nm}$ and was measured again every $24 \mathrm{~h}$ until when the absorbance of the control reached the maximum value. The percent inhibition of peroxidation was calculated as: $(\%)$ inhibition $=100-[$ (absorbance 
increase of the sample/absorbance increase of the control) $\times 100]$. Vitamin C and BHA used as positive control.

\section{Assay of putative biological active components}

Gallic acid

A Knauer series liquid chromatograph system and diode array detector was used. The column was a $\mathrm{C}_{18}$ reversed phase Kingsorb $5 \mathrm{~mm}(250 \times 4.6 \mathrm{~mm})$. Mobile phase was methanol/ water/ orthophosphoric acid (20/79.9/0.1) and the flow rate was $1.0 \mathrm{~mL} / \mathrm{min}$. Absorption wavelength was selected at $210 \mathrm{~nm}$. The content of gallic acid was calculated on the basis of a calibration curve constructed using authentic reference gallic acid.

\section{Quercetin}

The mobile phase was methanol/ acetonitrile/ water $(40: 15: 45, \mathrm{v} / \mathrm{v} / \mathrm{v})$ containing $1 \%$ acetic acid. This mobile phase was filtered through a $0.45 \mu \mathrm{m}$ membrane filter (Millipore). Quercetin was quantified by DAD following HPLC separation $368 \mathrm{~nm}$. Flow rate and injection volume were $1.0 \mathrm{~mL} / \mathrm{min}$ and $10 \mu \mathrm{L}$, respectively. The chromatographic peaks of the analyses were confirmed by comparing their retention time and those of the reference standards.

\section{Coumarin}

The column used was a $\mathrm{C}_{18}$ reversed phase Kingsorb $5 \mathrm{~mm}(250 \times 4.6 \mathrm{~mm})$. Separations were done in the isocratic mode, using acetonitrile: water $(40: 60 ; \mathrm{v} / \mathrm{v})$ at a flow rate of $1 \mathrm{~mL} \mathrm{~min}^{-1}$ with $\mathrm{UV}$, detection was at 274 nm.

\section{Statistical analysis}

Data were analyzed by one-way ANOVA followed by Turkey-Kramer tests. Antihypoxic activity was expressed relative to the control and was compared by Student's paired $t$-test. Results were considered significant at $p<0.05$.

\section{Results and Discussion}

Total phenol compounds were reported as gallic acid equivalents by reference to standard curve $\left(\mathrm{y}=0.0054 \mathrm{x}+0.0628, \mathrm{r}^{2}=0.987\right)$. The total phenolic content was $71.7 \pm 3.2 \mathrm{mg}$ gallic acid equivalent $/ \mathrm{g}$ of extract. The total flavonoid contents was $61.7 \pm 2.7 \mathrm{mg}$ quercetin equivalent/g of extract, by reference to standard curve $\left(y=0.0063 x, r^{2}=0.999\right)$. The amount of coumarin, quercetin and gallic acid determined by HPLC/DAD, has been shown in Table 1.

Table 1. The amount of some flavonoids detected in Juglans regia flower extract.

\begin{tabular}{lccc}
\hline Sample name & Quercetin & Gallic acid & Coumarin \\
\hline Juglan regia & 0.175 & 0.387 & trace \\
\hline Trace: concentration $<0.10 \mu \mathrm{g} / \mathrm{mg}$. \\
\end{tabular}

Phenols and polyphenolic compounds, such as flavonoids have been shown to possess significant antioxidant activities (Ebrahimzadeh et al., 2010a). Extract produced statistically significant inhibition of edema induced by carrageenan at nearly all doses when compared to the control groups (Table 2). The effect was dose-dependent. The highest activity showed at $1000 \mathrm{mg} / \mathrm{kg}$ i.p. that inhibited $77 \%$ of inflammation. The same activity was found for diclofenac at $100 \mathrm{mg}$ $/ \mathrm{kg}$ i.p. (73\%) ( $p>0.05)$. The Carrageenin test is highly sensitive to non-steroidal anti-inflammatory drugs, and has long been accepted as a useful tool for investigating new drug therapies (Just et al., 1998). Extract produced statistically significant inhibition of edema at all doses when compared to the control groups (Table 2).

Anti-inflammatory activity of gallic acid (Kroes et al., 1992) and quercetin (Morikawa et al., 2003) were reported previously and we believe that the anti-inflammatory activity of extract might be due to of presence of this or these compounds. Extract exhibits no toxicity up to $4 \mathrm{~g} / \mathrm{kg}$ body weight when injected i.p. in mice. A statistically significant antihypoxic activity of the extract was established in the experimental model of haemic and circulatory hypoxia in mice. The effects were found to be dose-dependent in both tests (Table 3). Administration of sodium fluoride increases the blood histamine content and decreases the oxygen carrying capacity (Sumina et al., 1978).

A significant protective effect on hypoxia has been reported by plants contains flavonoids (Karcher et al., 1984). Our results may be supported by other literature data that flavonoids increase cerebral blood flow and possess antihypoxic activity. The mechanism of this protective action may be in part due to the antioxidant activity of quercetin (Meli et al., 1990). The extract showed significant protective effect against hypoxia. In FST, extract at doses of 1000 and 1500 $\mathrm{mg} / \mathrm{kg}$ significantly and dose dependently reduced the immobility period to $110.1 \pm 4.1$ and $90.2 \pm 6.6 \mathrm{~s}$, respectively as compared to control mice of $164.2 \pm 11.3$ s $(p<0.001)$, imipramine showed significant antiimmobility activity with immobility time of $88.0 \pm 7.3$ $\mathrm{s}$ in comparison to its corresponding control group $(164.2 \pm 11.3 \mathrm{~s}) \quad(p<0.001)$. Extract at $1500 \mathrm{mg} / \mathrm{kg}$ showed the same activity as imipramine $(p>0.05)$. In TST model, extract (500 and $1000 \mathrm{mg} / \mathrm{kg}$ ) decreased significantly and dose dependently the immobility time 
Table 2. Anti-inflammatory activity of Juglans regia flower on carrageenan induced paw edema in rats.

\begin{tabular}{|c|c|c|c|c|c|}
\hline Treatment & Dose (mg/kg i.p.) & $\begin{array}{c}\text { Initial paw } \\
\text { thickness }(\mathrm{cm})(\mathrm{b})\end{array}$ & $\begin{array}{l}\text { Paw thichness } \\
\text { after } 3 \mathrm{~h}(\mathrm{~cm})(\mathrm{a})\end{array}$ & $\begin{array}{l}\mathrm{a} / \mathrm{b} \\
\text { ratio }\end{array}$ & Inhibition (\%) \\
\hline Solvent & Vehicle & $0.20 \pm 0.02$ & $0.46 \pm 0.02$ & 2.3 & 0 \\
\hline J. regia & 250 & $0.20 \pm 0.02$ & $0.44 \pm 0.03$ & $2.2^{\mathrm{ns}}$ & 7.7 \\
\hline J. regia & 500 & $0.30 \pm 0.02$ & $0.48 \pm 0.02$ & $1.7 * * *$ & 30.7 \\
\hline J. regia & 750 & $0.28 \pm 0.03$ & $0.42 \pm 0.02$ & $1.5^{* * *}$ & 46.2 \\
\hline J. regia & 1000 & $0.30 \pm 0.04$ & $0.36 \pm 0.01$ & $1.2 * * *$ & 76.9 \\
\hline Diclofenac & 100 & $0.23 \pm 0.02$ & $0.30 \pm 0.02$ & $1.30 * * *$ & 73.1 \\
\hline
\end{tabular}

${ }^{a}$ A ratio less than 1.5 was considered to be a significant inhibitory effect. Values are mean $\pm \mathrm{SD}(\mathrm{n}=6)$, NS, not significant, $* * * p<0.001 \mathrm{with}$ respect to control.

Table 3. Anti-hypoxic activity of Juglans regia flower in the different tests.

\begin{tabular}{lccc}
\hline Group & Doses $(\mathrm{mg} / \mathrm{kg})$ & $\begin{array}{c}\text { Sodium nitrite test } \\
(\mathrm{min})\end{array}$ & $\begin{array}{c}\text { Sodium fluoride } \\
\text { test }(\mathrm{min})\end{array}$ \\
\hline Control & & $9.50 \pm 0.30$ & $9.36 \pm 0.32$ \\
J. regia & 31.25 & $10.08 \pm 0.10^{* *}$ & - \\
J. regia & 62.5 & $10.52 \pm 0.60^{* * * *}$ & $10.23 \pm 0.11^{*}$ \\
J. regia & 125 & $12.03 \pm 0.39 * * * *$ & $11.71 \pm 0.37 * *$ \\
J. regia & 250 & - & $15.63 \pm 0.65^{* * *}$ \\
\hline
\end{tabular}

Each group represents the mean $\pm \mathrm{SD}(\mathrm{n}=10) . *$ Not significant, $* * p<0.05$, $* * * p<0.01$ and $* * * * p<0.001$ vs. control.

to $114.3 \pm 15.1$ and $79.9 \pm 3.4 \mathrm{~s}$, respectively, as compared to control mice of $157.8 \pm 12 \mathrm{~s}(p<0.001)$ (Table 4).

Imipramine decreased significantly the immobility period to $74.2 \pm 6.3 \mathrm{~s}$ in comparison to control $(157.8 \pm 12 \mathrm{~s})(p<0.001)$. Extract at $1000 \mathrm{mg} /$ $\mathrm{kg}$ showed the same activity as imipramine $(p>0.05)$. These models represent the behavioral despair models, claimed to reproduce a condition similar to human depression (Lucki, 1997). TST detects the antiimmobility effects of a wide array of antidepressants, including tricyclic antidepressants, selective serotonin reuptake inhibitors, monoamine oxidase inhibitors and atypical antidepressants (Mahmoudi et al., 2009). Thus, the activity of extract could involve one of the mechanisms of the established agents as described above. Antidepressant activity of extract may be due to high flavonoids content, especially quercetin in this species. IC50 for DPPH radical scavenging activity was $674 \pm 27.6 \mu \mathrm{g} \mathrm{mL}^{-1}$. The IC50 values for vitamin $\mathrm{C}$, quercetin and BHA were 5.1 $\pm 0.1,5.9 \pm 0.2$ and $53.9 \pm 3.1$ $\mu \mathrm{g} \mathrm{mL}^{-1}$, respectively. DPPH is a stable nitrogencentered free radical, which its color changes from violet to yellow upon reduction. Substances which are able to perform this reaction can be considered as radical scavengers (Nabavi et al., 2008). Phenol and flavonoid contents of this plant may be responsible for the DPPH-scavenging activity. The extract also showed significant $\mathrm{Fe}^{2+}$ chelating ability. IC50 was $43 \pm 1.5$
Table 4. Effect of methanol extract of Juglans regia flower on the duration of immobility during forced swimming test and Tail suspension test.

\begin{tabular}{lccc}
\hline Group & $\begin{array}{c}\text { Doses } \\
(\mathrm{mg} / \mathrm{kg})\end{array}$ & $\begin{array}{c}\text { Duration of } \\
\text { immobility (s), FST }\end{array}$ & $\begin{array}{c}\text { Duration of } \\
\text { immobility (s), TST }\end{array}$ \\
\hline Control & - & $164.2 \pm 11.3$ & $157.8 \pm 12$ \\
J. regia & 250 & $154.67 \pm 12.9^{*}$ & $141.6 \pm 7.8^{*}$ \\
J. regia & 500 & $122.89 \pm 8.4^{* *}$ & $114.3 \pm 15.1^{* *}$ \\
J. regia & 1000 & $110.10 \pm 6.2^{* *}$ & $79.38 \pm 5.4^{* *}$ \\
J. regia & 1500 & $90.14 \pm 6.6^{* *}$ & - \\
Imipramine & 15 & $88 \pm 7.3^{* *}$ & $74.2 \pm 6.3^{* *}$ \\
\hline
\end{tabular}

Each group represents the mean $\pm \mathrm{SD}(\mathrm{n}=10) .{ }^{*} p>0.05$ and ${ }^{* *} p<0.001 \mathrm{vs}$. control.

$\mu \mathrm{g} \mathrm{mL}^{-1}$. EDTA showed strong activity (IC50 18 \pm 0.4 $\left.\mu \mathrm{g} \mathrm{mL}^{-1}\right)$. Chelation therapy reduces iron-related complications in human and thereby improves quality of life and overall survival in some diseases such as Thalassemia major (Hebbel et al., 1990). Ferrozine can form complexes with $\mathrm{Fe}^{2+}$. At the presence of other chelating agents, the complex formation is disrupted and red color of the complexes decreases. In this assay, both extract and EDTA interfered with the formation of ferrous and ferrozine complex, suggesting that it has chelating activity and captures ferrous ion before ferrozine. The extract showed weak NO scavenging activity between $400-1600 \mu \mathrm{g} \mathrm{mL} \mathrm{m}^{-1}$ (20.4\% inhibition in $1600 \mu \mathrm{g} \mathrm{mL} \mathrm{mL}^{-1}$ vs. quercetin with IC50 17.01 \pm 0.6 $\left.\mathrm{mg} \mathrm{mL}^{-1}\right)$. The procedure is based on the principle that sodium nitroprusside at physiological $\mathrm{pH}$ generates NO which interacts with oxygen to produce nitrite ions that can be estimated using Griess reagent. Scavengers of NO compete with oxygen, leading to reduced production of nitrite ions. Figure 1 shows antioxidant activity of the extract using FTC method. There were significant differences between extract and controls $(p<0.05)$.

\section{Conclusion}

J. regia flower showed remarkable antihypoxic, anti-inflammatory, antioxidant and antidepressant activities in safe dose, which may be due to its high 
phenol and flavonoid contents, especially quercetin. It is therefore very promising for further pharmacological and biochemical experiments.

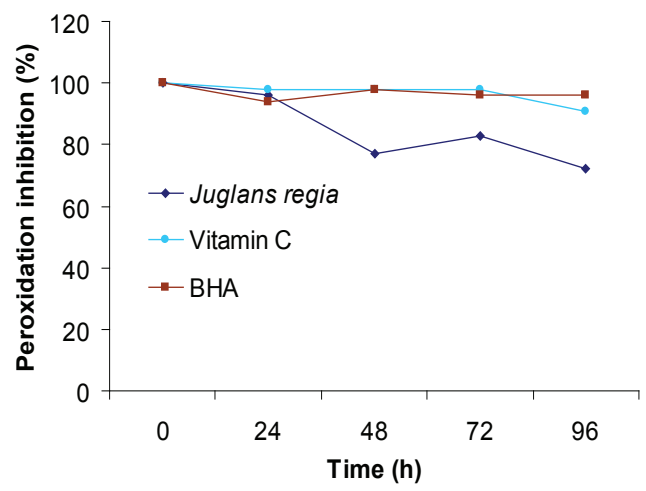

Figure 1. Antioxidant activities of Juglans regia flower extract in linoleic acid peroxidation test. Each value is expressed as mean of three measurements. Vitamin C and BHA were used as positive control.

\section{Acknowledgments}

This research supported by a grant from pharmaceutical sciences research center, Mazandaran, Iran. The paper is dedicated to corresponding author's young daughter, Monica. Some parts of this research were a M.D. thesis. Authors would like to thank Dr Pakravan for her English editing.

\section{References}

Almeida IF, Fernandes E, Lima JLFC, Costa PC, Bahia MF 2008. Walnut [Juglans regia] leaf extracts are strong scavengers of pro-oxidant reactive species. Food Chem 106: 1014-1020.

Asgary S, Parkhideh S, Solhpour A, Madani H, Mahzouni P, Rahimi P 2008. Effect of ethanolic extract of Juglans regia L. on blood sugar in diabetes-induced Rats. $J$ Med Food 11: 533-538.

Dehpour AA, Ebrahimzadeh MA, Nabavi SF, Nabavi SM 2009. Antioxidant activity of the methanol extract of Ferula assafoetida and its essential oil composition. Grasas Aceites 60: 405-412.

Ebrahimzadeh MA, Mahmoudi M, Salimi E 2006. Antiinflammatory activity of sambucus ebulus hexane extracts. Fitoterapia 77: 146-148.

Ebrahimzadeh MA, Mahmoudi M, Karami M, Saeedi SS, Ahmadi AH, Salimi E 2007. Separation of active and toxic portions in Sambucus ebulus. Pak J Biol Sci 10: 4171-4173.

Ebrahimzadeh MA, Pourmorad F, Bekhradnia AR 2008. Iron chelating activity screening, phenol and flavonoid content of some medicinal plants from Iran. Afr $J$ Biotechnol 7: 3188-3192.

Ebrahimzadeh MA, Nabavi SM, Nabavi SF 2009. Correlation between the in vitro iron chelating activity and poly phenol and flavonoid contents of some medicinal plants. Pak J Biol Sci 12: 934-938.

Ebrahimzadeh MA, Nabavi SF, Nabavi SM, Eslami B 2010a. Antihypoxic and antioxidant activity of Hibiscus esculentus seeds. Grasas Aceites 61: 30-36.

Ebrahimzadeh MA, Nabavi SF, Nabavi SM, Eslami B 2010b. Antihemolytic and antioxidant activities of Allium paradoxum. Cent Eur J Biol 5: 338-345.

Ebrahimzadeh MA, Nabavi SF, Nabavi SM, Mahmoudi M, Eslami B, Dehpour AA 2010c. Biological and pharmacological effects of Delphinium elbursense. Afr J Biotechnol 9: 5548-5555.

Ebrahimzadeh MA., Nabavi SF., Nabavi SM., Pourmorad F 2010d. Nitric oxide radical scavenging potential of some Elburz medicinal plants. Afr J Biotechnol 9: 5212-5217.

Erdemoglu N, Küpeli E, Ilada EY 2003. Anti-inflammatory and antinociceptive activity assessment of plants used as remedy in Turkish folk medicine. J Ethnopharmacol 89: 23-129.

Fukuda T, Ito H, Yoshida T 2003. Antioxidative polyphenols from walnuts (Juglans regia L.). Phytochemistry 63: 795-801.

Ghasemi K, Ghasemi Y, Ebrahimzadeh MA 2009. Antioxidant activity, phenol and flavonoid contents of 13 Citrus species peels and tissues. Pak J Pharm Sci 22: 277281.

Hebbel RP, Leung A, Mohandas N 1990. Oxidation-induced changes in microheological properties of the red cell membrane. Blood 76: 1015-1022.

Just MJ, Recio MC, Giner RM, Cuellar MJ, Manez S, Bilia AR, et al., 1998. Antiinflammatory activity of unusual lupine saponins from Bupleurum fruticescens. Planta Med 64: 404-407.

Karcher L, Zagermann P, Krieglstein J 1984. Effect of an extract of Ginkgo biloba on rat brain energy metabolism in hypoxia. Naunyn Schmiedebergs Archive of Pharmacology 327: 31-35.

Kroes BHm van den Berg AJ, Quarles van Ufford HC, van Dijk H, Labadie RP 1992. Anti-inflammatory activity of gallic acid. Planta Med 58: 499-504.

Lucki I 1997. The forced swimming test as a model for core and component behavioural effects of antidepressant drugs. Behav Pharmacol 8: 523-532.

Mahmoudi M, Ebrahimzadeh MA, Ansaroudi F, Nabavi SF, Nabavi SM 2009. Antidepressant and antioxidant activities of Artemisia absinthium L. at flowering stage. Afr J Biotechnol 8: 7170-7175.

Mahmoudi M, Ebrahimzadeh MA, Nabavi SF, Hafezi S, Nabavi SM, Eslami Sh 2010. Antiinflammatory and antioxidant activities of gum mastic. Eur Rev Med Pharmacol Sci 14: 765-769.

Meli R, Authore G, Di Carlo G, Capasso F 1990. Inhibitory action of quercetin on intestinal transit in mice. 
Phytotherapy Res 5: 201-203.

Morikawa K, Nonaka M, Narahara M, Torii I, Kawaguchi K, Yoshikawa T, Kumazawa Y, Morikawa S 2003. Inhibitory effect of quercetin on carrageenan-induced inflammation in rats. Life Sci 74: 709-721.

Nabavi SM, Ebrahimzadeh MA, Nabavi SF, Hamidinia A, Bekhradnia AR 2008. Determination of antioxidant activity, phenol and flavonoids content of Parrotia persica Mey. Pharmacologyonline 2: 560-567.

Sumina E, Shugaev V, Shugaev V 1978. The mechanism of circulatory hypoxia in acute poisoning with sodium fluoride poisoning. Farmakol Toksikol 41: 480-482.

\section{*Correspondence}

Mohammad Ali Ebrahimzadeh

School of Pharmacy, Mazandaran University of Medical Sciences

Sari, Iran

mebrahimzadeh@mazums.ac.ir

Tel.: +98 $1513543081-3$

Fax: +98 1513543084 